\title{
Prototype Development of Garsupati: A Single Access to Open Educational Resources
}

\author{
I Ketut Resika Arthana ${ }^{1}$, I Made Putrama ${ }^{2}$ \\ ${ }^{1,2}$ Department of Informatics Technology Education \\ ${ }^{1,2}$ Faculty of Engineering and Vocational \\ ${ }^{1,2}$ Universitas Pendidikan Ganesha, Singaraja Indonesia \\ ${ }^{1}$ resika@undiksha.ac.id, ${ }^{2}$ made.putrama@undiksha.ac.id
}

\author{
Harry Budi Santoso ${ }^{1}$, Zainal Arifin Hasibuan ${ }^{1}$ \\ ${ }^{1,2}$ Digital Library \& Distance Learning Lab \\ ${ }^{1,2}$ Faculty of Computer Science \\ ${ }^{1,2}$ Universitas Indonesia \\ ${ }^{1}$ harrybs@cs.ui.ac.id, ${ }^{2}$ zhasibua@cs.ui.ac.id
}

\begin{abstract}
- nowadays there are many stakeholders to provide content learning and courseware on their website with their platform. They use various platforms such as Open Course Ware (OCW), Learning Management System (LMS), Open Journal System and other website with custom development. The problem from current condition is the user must visit this each website to searching content learning or courseware. This activity made user wasting their time because there are no single access to OER. Another problem is no definition of the relationship between learning content. One of issue on OER is lack of learning content resources and guarantee quality of content. On this research, we address this problem with develop prototype portal Garda Sumber Pembelajaran Terbuka Indonesia (Garsupati) to give single access to Open Educational Resources (OER). On Garsupati, users can search and view learning content and courseware, give rating and comment to evaluate learning content, define relationship between learning content, contribute learning content and courseware. To enrich collection on Garsupati, apart from using user's contribution, Harvesting and Crawling techniques are used to collect the metadata of learning content and courseware. The scope of current research is until the prototype development of the Garsupati.
\end{abstract}

Keywords : OER, Garsupati, Learning Content, Harvesting and Crawling

\section{INTRODUCTION}

Education plays an important role in improving the quality of human resources to improve the welfare of society. One important issue in education is education equity. The differences in the quality of human resources, technology and geographic distribution cause the unequal quality of education. However, with advances in technology, especially proliferation of computers and the Internet, educational equity issues solved sooner.

The internet plays an important role to distribute education and change the way of the people learns. Educational resources from textbooks and electronically educational resources can be accessed from Internet. On the other hand, educational resources produced from university, school, industry and government. The educational resources can be accessed and can be used to improve educational. This phenomenal we call it Open Educational Resources (OER).
OER is a source of teaching, learning, and research that is in the public domain or has been released under an intellectual property license that allows free use and reuse by others. Open educational resources include full courses, course materials, modules, textbooks, streaming videos, tests, software, and any other tools, materials, or techniques used to support access to knowledge[1]. Educational Resources consists of educational software and make it possible to be created and adopted for use in teaching.

OER project is supported by UNESCO, many academic community and practitioners around the world. For example, MIT Open Courseware has opened all course material by online and free. The World Bank has launch Knowledge Repository consist of collection of publication under CreativeCommons licenses. Some countries such as Brazil given mandate to open all educational resources and funded by government. The Indonesian Government through the Law No. 12 of 2012 on Higher Education chapter 79 verses 4 says that the Government develops open educational resources that can be utilized by the entire academic community. In addition, Higher Education through a circular 125 / E / T / 2012 requires the Undergraduates publish a journal as a graduation requirement. The real impact of this Act is the increased sources of Open Learning called Open Course Ware (OCW) and the emergence of student journals that can be accessed online.

The open educational resources materials are published by various groups using a variety of technologies, platforms and different formats. Some publish it only as a content and while the others publish it into the lecture series. In addition, they use many different technologies to publish content such as through MediaWiki, Moodle or OCW. The problem that arises is the difficulty in identifying and linking between the material and it is not easy to search in finding specific open source education. These shortcomings can be due to the lack of relevant information which support the shared open educational resources as well as the fact that the open educational resources are published through various sites which might be unknown to the users

The information provided on the content or source of learning could be in the form of metadata. One example of metadata used to describe the digital document is Dublin Core. 
While in OER, there is LRMI that is used to define the OER objects. In addition, there should be a need to define the relationship between the content open the educational resources. The technology that can be used to overcome this problem is by using Resource Data Framework (RDF). RDF is a framework for defining the relationship between the data as a couple of properties and values. RDF document is written in XML format. By using RDF, the standardized syntax allows the exchange of information between sites.

In accordance with the above problems, the research will develop an OER portal using metadata standards and RDF. This system will be called the Garda Open Learning Resources Indonesia (a.k.a. Garsupati). Garsupati serves as a gateway to other open educational resources as well as defining metadata and relationships between learning content.

\section{STATE OF THE ART}

The emerging technologies, especially the increasing number of devices that can be used by humans to communicate and utilize the Internet are positive impacts on education. The use of technology is often associated with the use of electronic learning in education. Utilization of e-Learning support effective learning, while providing the freedom for students to learn anytime, anywhere and anyhow according to what they need[2]. Utilization content in E-learning would be more useful if it is used again or divided as other learning resources. The concept of sharing and reuse of learning resources is also known as OER.

OER provide free access to documents and media that are useful in the learning process. Research on the OER has been done mainly in providing solutions to share and reuse open educational resources that already exists. There are many websites provide open learning nowadays. But from existing research, it was found that many websites do not already provide interfaces or metadata schemes for the exchange of open educational resources[3]. This has an impact that the lack of use of open educational resources. This shows that the problems of integrating open educational resources are an important issue in the OER.

In Indonesia, there has been an initiated movement towards the OER. It is, as already declared on 7-10 May 2013 at Hotel Ayodya, Bali. In the declaration organized by APTIKOM, the Indonesia OER portal was also introduced. In this portal, adopting OER framework consisting of three domains, namely the Open Content, Open Courseware and Open Campus. While the general architecture of Indonesia OER consists of Data Layer, Application Layer and Presentation Layer[4]. Data Layer consists of learning resources from the library, research labs, universities and other sources. The Application Layer consists of E-Administration, E-Library and ELearning. As for expanding access, the presentation layer is described that the access to OER can be done from multiple devices (Multichannel Access)[5]

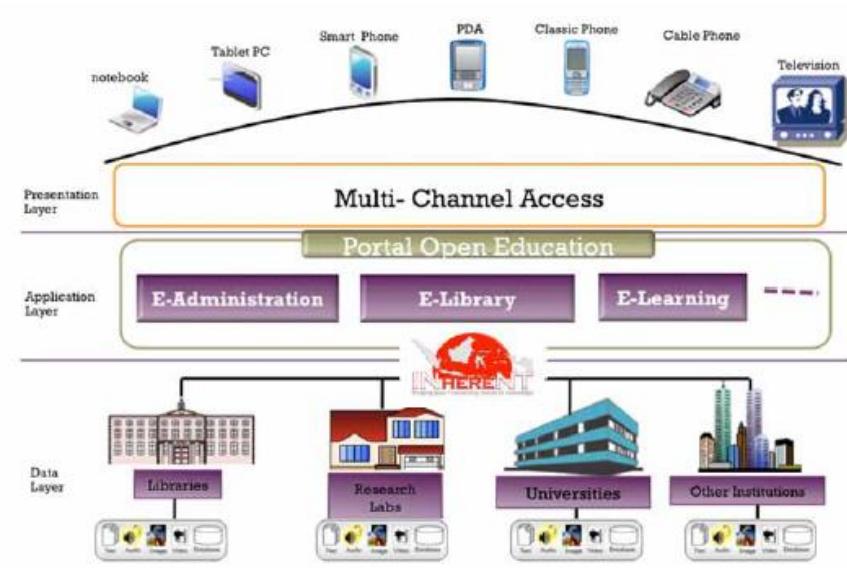

Figure 1. Open Education Architecture[4].

\section{METHODOLOGY}

We used ADDIE methodology to develop Garsupati. ADDIE consists of Analysis, Design, Development, Implementation and Evaluation. On analysis phase, we define functional and non- functional requirement, then on design phase we design user interface and database design. Then we developed the design to system and implement on Learning Object. The evaluation was done by verifying the correctness between the system requirements and the implementation.

\section{A. Analysis}

At this stage, an analysis towards the existing OER was done to get the OER content characteristics. Data collection methods for OER content are readily available through browsing to other OER systems and doing website crawling. In addition, we conducted a review to the standard metadata and the available RDF to match the characteristics of OER content. The goal at this stage is to get the standard metadata that defines the properties of OER content that can be generally applicable. Furthermore, we also obtained the standard relationship between OER content. These standards were used as material for determining the list of system requirements on Garsupati.

\section{Functional Requirements}

Based on the analysis that has been done, it can be formulated the Use Case Diagram as follows: 


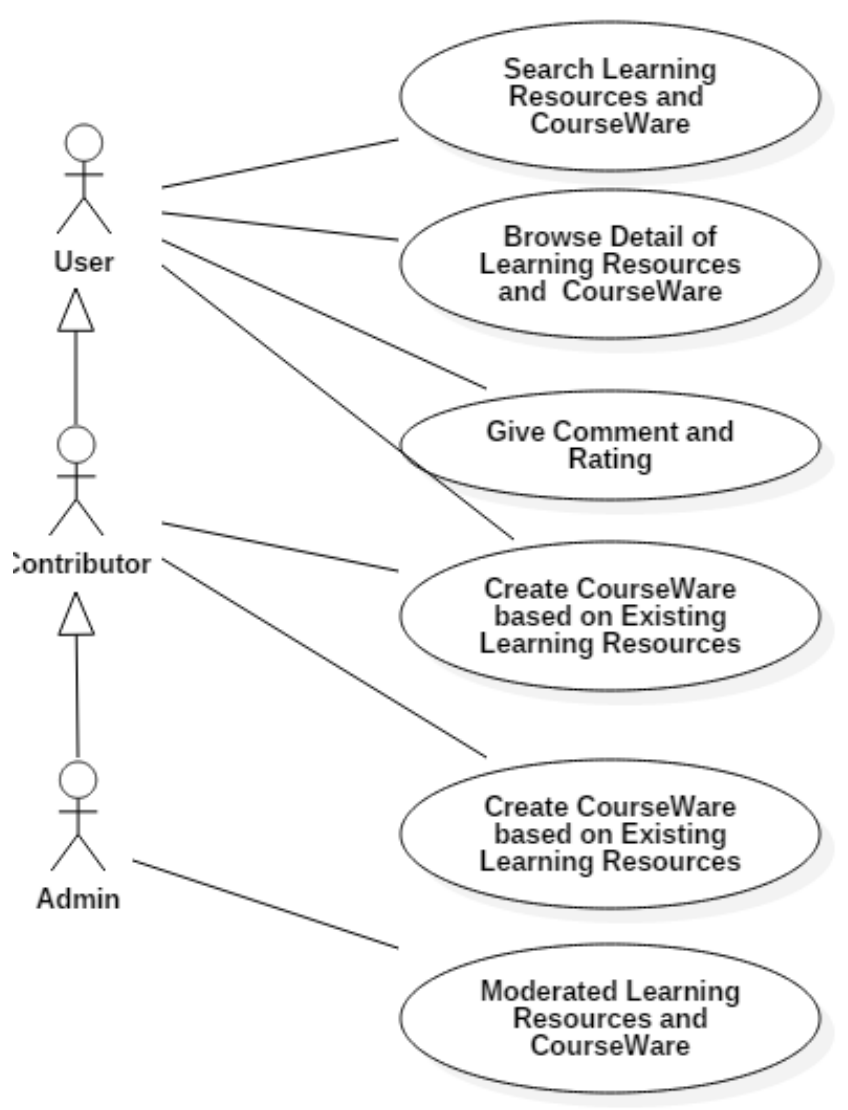

Figure 2. Use Case of Garsupati

1) Users can search for learning resources in the form of teaching content and courseware

a. Users can search by field of science (subject area)

b. Users can search by educational level

2) Users can view details of teaching resources and courseware

3) Users can leave ratings and comments on the content of teaching and the courseware

4) Users can report the teaching content and courseware that is not appropriate

5) Contributors can donate instructional content

a. Upload a full teaching resources

b. Upload teaching resources information that exists on other sites.

6) Contributors can create courseware by combining the resources of learning in Garsupati

7) Admins can moderate the teaching resources listed at Garsupati

8) The system can retrieve the data of the open learning sources
a. Using harvesting techniques for systems using
OAI protocol
b. Use RSS

9) The system can provide recommendations of related topics
2. Non-Functional Requirements

List of non-functional requirements support the fulfillment of the functional requirements as follows:
a. The web-based system made in accordance with the aspect of Usability
b. Data instructional content using Dublin Core metadata standard

\section{B. Design}

At this stage, the list of system requirements obtained in the analysis stage is used to draft the Garsupati. The designs include architectural design, user interface design and design associated with communication between OER systems that exchange metadata.

\section{Development}

The designs that have been obtained at the Design stage are developed by encoding using predetermined tools. Garsupati system is built using the programming language PHP, My SQL database, Metadata Parser using Java, and the provided service is published using GlashFish Web Server. OAI protocol is also implemented at this stage.

\section{Implementation}

Garsupati system is implemented on the server and connected to other OER. Users will do browsing and searching through Garsupati. Garsupati provide the OER content searched results that link to the other OER content.

\section{E. Evaluation}

The evaluation was done at each stage above for improvement during the Garsupati development. However, in the final stages of the overall evaluation was also conducted to ensure the developed Garsupati system meets the functional requirements that have been defined previously. Evaluations undertaken include:

a. Compliance with Functional Needs

b. Compliance with Non-Functional Requirements

c. Suitability standard metadata and RDF 


\section{RESULTS}

\section{A. Database}

Garsupati database consists of entities whose function is to store learning content and courseware. Garsupati does not save the entire content, but it only saves the descriptions in the form of metadata. The learning content refers to the original source.

\section{B. Data Collection Method \\ a) User Contribution}

Learning content obtained through user contributions. Users, who have learning content, can contribute their content in Garsupati. Users who know the source of quality learning can also contribute the information into Garsupati.

\section{b) Harvesting}

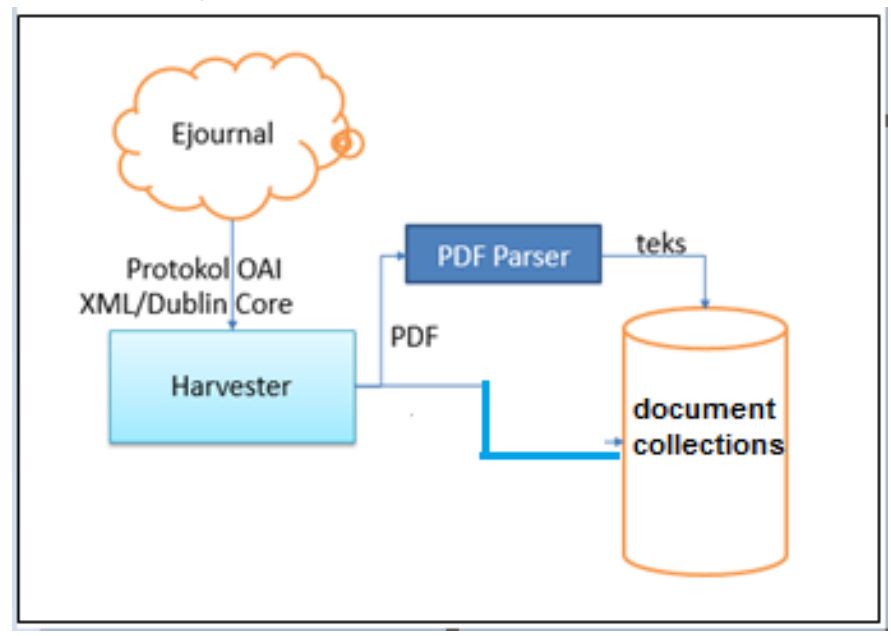

Figure 3. Harvesting Architecture

Harvester aimed at harvesting (collecting) metadata from OAI link. Harvester produces the journal metadata to XML format. Then the file is parsed and stored into the database. Content contained in XML form of the title, abstract and keywords. Overall, there are no documents in the XML. To obtain the full text document then a crawling based on the XML link is done to the entire document. If the documents can be obtained the document will be parsed into texts and stored into the database.

In this study, the harvester is implemented using Java programming language, Web Server Glassfish and JOAI library. Here is a piece of program code in doing the harvester procedure.

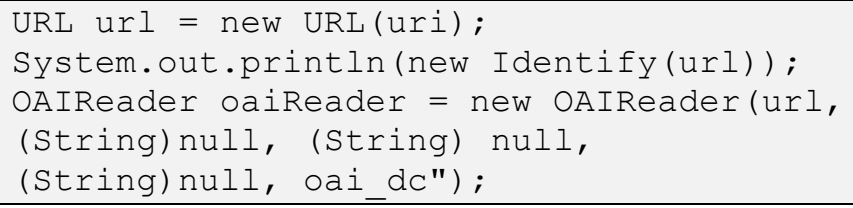

Program code snippet XML parsing section is as follows.

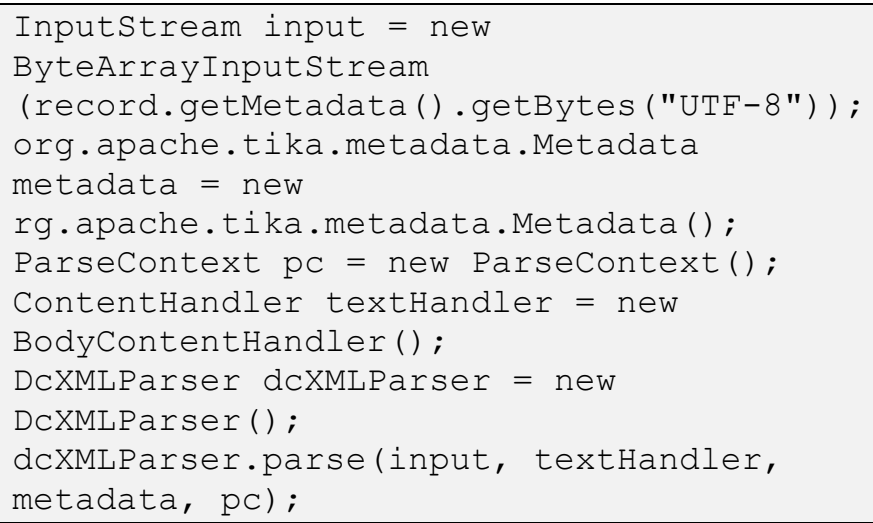

The results from harvesting proccess is a metadata Dublin Core used to do document collection inGarsupati. In the Garsupati, the learning content is just a metadata content, not the full content. If user want to see the detail of the learning content, user just need to follow the provided link on the metadata content.

\section{Garsupati Prototype}

\section{a) Main Page}

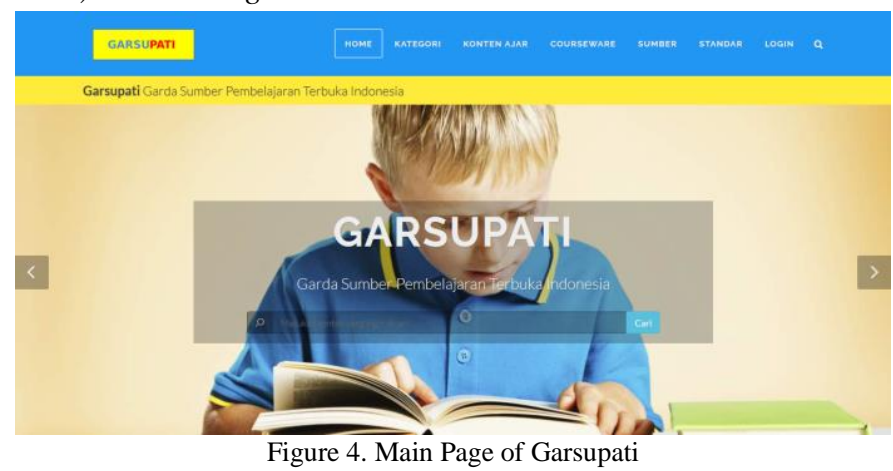

Garsupati main page is the first page that will be viewed by the user. The main page contains brief information about Garsupati and search pages. This search page is the user entrance to search all the open educational resources information recorded on Garsupati. After writing the keywords and pressing the search button, Garsupati shall display a list of open educational resources and its related courseware. 
b) Learning resources page and CourseWare

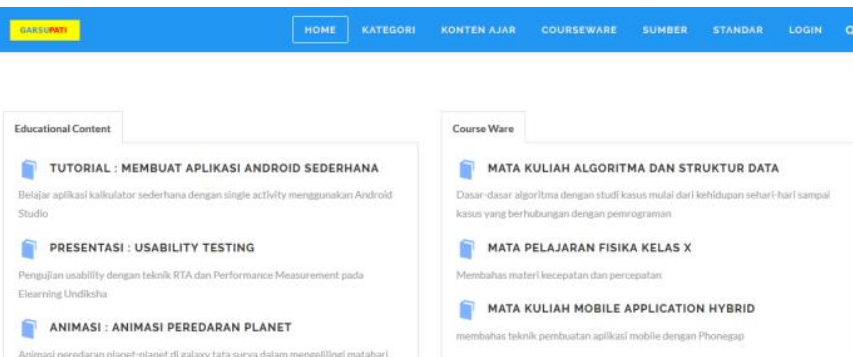

Figure 5. Learning Resources and CourseWare

On this page, it is shown a list of teaching resources and courseware that is available in the Garsupati website. The source of teaching materials and courseware comes from user contributions and from websites crawling done by Garsupati system. The materials here could be the actual materials or only certain links to learning resources. Courseware is a collection of learning resources that are connected with each other based on certain topics and sub-topics.

\section{Home learning resources and CourseWare}

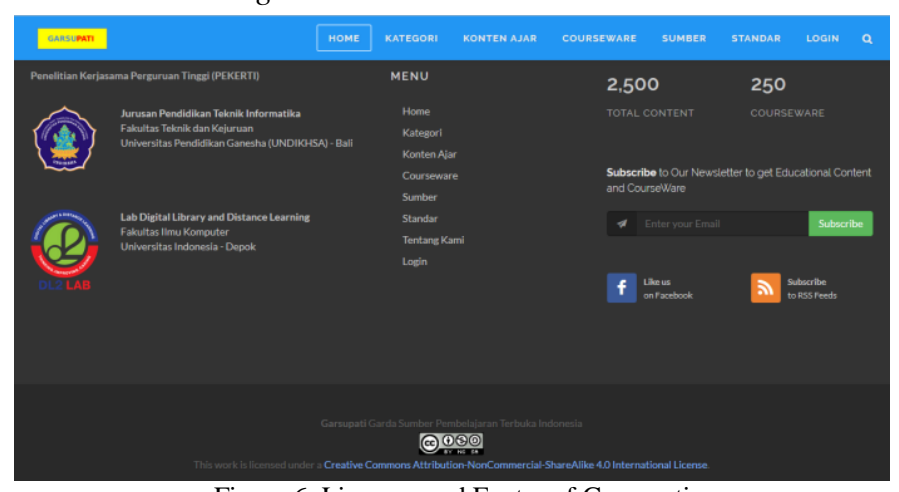

Figure 6. Licenses and Footer of Garsupati

On this page, Garsupati displays links related to cooperation, menus and lists of licenses. The Garsupati license adopts a Creative Commons license with the type of license: Attribution, Non-Commercial and Share Alike.

\section{E. Category on Garsupati}

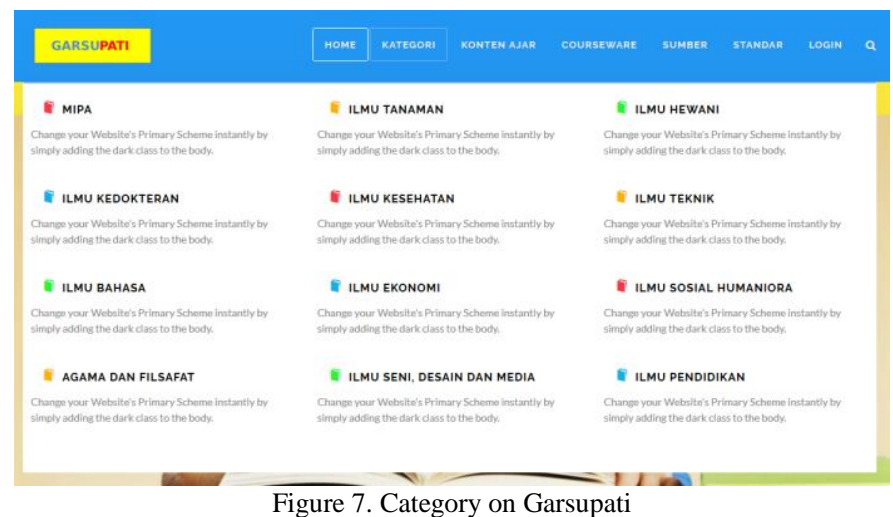

Figure 7. Category on Garsupati
This page displays the menu listing categories of the available resources and courseware. The way it is categorized is adopted from the science categories set by the Higher Education. Once this menu is clicked, it will display a list of sources of teaching and the appropriate courseware discipline.

\section{F. Contributions to the Content Learning}

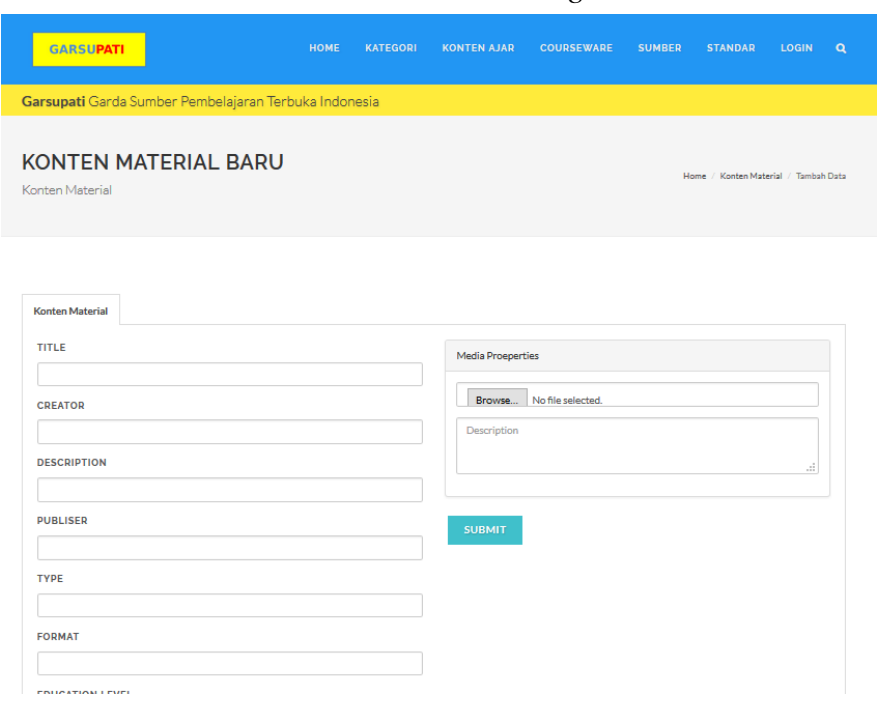

Figure 8. Contribution to Garsupati

Users can contribute their own content / material to be shown on the website. The content source can be one's own or a reference to another content source.

\section{CONCLUSION}

This research has carried out the analysis of open educational resources such as standards related to open educational resources that already exist, the development of systems and content open educational resources that already exist in Indonesia. Based on this analysis, subsequently designed functional and non-functional requirements were gathered as a reference in developing Garsupati system. The standards used in describing learning content refer to the Dublin Core standard. At this research stage, the Garsupati system prototype has been done. The main feature in Garsupati are single access to OER, On Garsupati, users can search and view learning content and courseware, give rating and comment to evaluate learning content, define relationship between learning content, contribute learning content and courseware 


\section{REFERENCES}

[1] Z. Rimale, "A Semantic Learning Object ( SLO ) Web-Editor based on Web Ontology Language ( OWL ) using a New OWL2XSLO Approach," vol. 7, no. 12, pp. 315-320, 2016.

[2] M. Meyer, C. Rensing, and R. Steinmetz, "Multigranularity reuse of learning resources," ACM Trans. Multimed. Comput. Commun. Appl., vol. 7, no. 1, pp. 1-23, 2011.

[3] H. Barros, E. Costa, J. Magalhães, and R. Paiva, "Integrating educational repositories to improve the reuse of learning objects," Proc. ACM Symp. Appl. Comput., vol. 13-17-Apri, pp. 270-272, 2015.
[4] Nizam and A. Santoso, "Indonesia : OER Initiatives \& ICT in Teachers Training," 2013.

[5] R. F. Aji, I. K. R. Arthana, H. Yaniar, and Z. A. Hasibuan, "Architecture Multichannel-Access of Information Retrieval System Case Study: Indonesian E-Cultural Heritage and Natura History Portal," in International Conference on Computer Engineering and Applications, 2011. 